\title{
Navigating the complexity of percutaneous coronary intervention in patients at high risk for bleeding
}

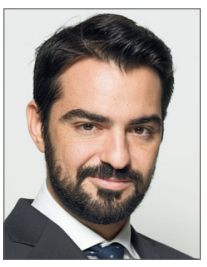

Gennaro Giustino, MD; Roxana Mehran*, MD

The Zena and Michael A. Wiener Cardiovascular Institute, The Icahn School of Medicine at Mount Sinai, New York, NY, USA

The co-evolution of coronary stent technologies and antithrombotic pharmacotherapies has been driven by the delicate balance of two opposing forces: bleeding and thrombosis ${ }^{1}$. The pathophysiological rationale of antithrombotic therapies after coronary stent implantation is predicated on the need to protect the stented vascular segment from device thrombosis while stent endothelialisation is ongoing ${ }^{2}$. However, all antithrombotic agents are associated with increased risk for bleeding, the magnitude of which is proportional to their intensity and time of exposure ${ }^{2}$. Compared with bare metal stents (BMS), early-generation drug-eluting stents (DES) required prolonged periods of dual antiplatelet therapy (DAPT) due to high rates of stent thrombosis $(\mathrm{ST})^{2}$. Iterations of DES technologies by improving polymer biocompatibility, drug release kinetics and patterns of endothelialisation overcame the limitations of earlygeneration DES and allowed more flexible and shorter periods of $\mathrm{DAPT}^{2}$. With current-generation devices, the risk of ST remains highest within 30 days and then declines over time ${ }^{3}$. Conversely, the risk of haemorrhagic complications and their consequences associated with the use of DAPT remain relatively constant over time or even increase as the patient ages or develops new comorbidities that predispose to bleeding ${ }^{4}$.

Currently, most percutaneous coronary interventions (PCI) with DES are performed in complex clinical and anatomical subsets of patients. Among these, patients at high bleeding risk (HBR) constitute a unique clinical conundrum given their predisposition to developing both haemorrhagic and thrombotic complications, therefore making the selection of devices and pharmacotherapy strategies challenging. On the other hand, the complexity of coronary artery disease (CAD) influences the effectiveness of PCI and is associated with a higher risk of adverse events, proportional to its severity and burden ${ }^{5}$. Recent evidence suggests that, for patients who require complex PCI, an initial period of DAPT of 12 months is associated with lower rates of major adverse cardiac events compared with a period $\leq 6$ months $^{5}$. However, such benefits in complex PCI patients seem to attenuate beyond the one year time landmark, when patient-related factors seem to be more important in determining the ongoing thrombotic risk compared with procedure-related factors ${ }^{6}$.

It is within this context that, in this issue of EuroIntervention, Lipiecki et al report the results of a post hoc analysis from the LEADERS FREE trial evaluating the interaction between HBR status, PCI complexity and the outcomes of polymer-free (PF) biolimus-eluting stents (BES) versus BMS followed by only one month of $\mathrm{DAPT}^{7}$.

\section{Article, see page 418}

The authors should be congratulated for undertaking this type of analysis which is the very first attempt to try to delineate the intricate relationship between HBR status and thrombotic risk as determined by procedural complexity. HBR status, the main inclusion criterion of the LEADERS FREE trial, was defined as any patient having one or more of the previously reported clinical criteria deemed to be associated with increased bleeding risk or requiring discontinuation of DAPT after one month $^{7}$. Complex PCI was defined according to a modified version of the Giustino et al criteria ${ }^{5}$, including any of the following elements or their combination: $\geq 3$ vessels stented, $\geq 3$ lesions treated, $\geq 3$ stents implanted, total stent length $\geq 60 \mathrm{~mm}$, bifurcation with $\geq 2$ stents implanted, a chronic total occlusion, an instent restenosis or a saphenous vein graft as target lesion. Using these criteria, a total of $667 / 2,413(27.6 \%)$ patients underwent a complex PCI procedure. Within the complex PCI group, compared with BMS, the use of PF-BES was associated with lower rates of the primary efficacy endpoint of clinically driven target 
lesion revascularisation ( $10.8 \%$ vs. $18.1 \%$; hazard ratio [HR] $0.54 ; 95 \%$ confidence interval $[\mathrm{CI}]: 0.35-0.83 ; \mathrm{p}<0.005)$ and of the composite primary safety endpoint of cardiac death, myocardial infarction or definite or probable ST (16.2\% vs. $21.7 \%$; HR $0.70 ; 95 \%$ CI: $0.49-0.99 ; \mathrm{p}=0.04)$, without evidence of interaction compared with the treatment effects within the non-complex PCI group $\left(\mathrm{p}_{\text {interaction }}=0.88\right.$ and $\mathrm{p}_{\text {interaction }}=0.34$, respectively). However, the absolute risk reductions (ARR) favouring PF-BES for both the primary efficacy and safety endpoints appeared to be greater within the complex PCI group (ARR: $-7.3 \%$, number needed to treat [NNT]: 14 ; and ARR: $-5.52 \%$, NNT: 18 , respectively) compared to the non-complex PCI group (ARR: $-4.6 \%$, NNT: 22; and ARR: $-1.5 \%$, NNT: 65, respectively). For the endpoint of definite or probable ST, PF-BES were associated with significantly lower rates on both the absolute scale (ARR: $-3.0 \%$; NNT: 33 ) and the relative scale (HR 0.36; 95\% CI: $0.40-$ $0.94)$ with significant statistical interaction compared with the non-complex PCI group $\left(\mathrm{p}_{\text {interaction }}=0.01\right)$.

These findings need to be put into perspective with the current evidence on optimal DAPT duration and prior reports focused on complex PCI. First, the event rates observed in the current report are substantially higher compared with those observed in the analysis of Giustino et al or Yeh et $\mathrm{al}^{5,6}$; this is most likely related to the unique population enrolled in the LEADERS FREE trial which included patients at very high risk of both thrombotic and bleeding events routinely excluded by conventional randomised controlled trials. Second, all patients received one month of DAPT compared with 3,6 or 12 months in the analysis by Giustino et $\mathrm{al}^{5}$ and with 12 or 30 months in the analysis by Yeh et $\mathrm{al}^{6}$. This is a crucial factor to consider in order to appraise these findings fully. Despite the use of a very abbreviated DAPT duration (one month), PF-BES were associated with significantly lower rates of ST compared with BMS, particularly within the complex PCI group. This finding provides reassurance regarding the excellent performance of PF-BES in HBR patients who require complex PCI and who cannot tolerate mandatory durations of DAPT of six or 12 months. Limitations of the current study include the post hoc nature of the analysis, inclusion of a relatively low sample size (only 667 patients with complex PCI) and lack of availability of data on baseline CAD complexity (SYNTAX score). In addition, no standardised criteria of complex PCI yet exist and the currently available definitions will need validation in other studies.

Where do we stand now regarding the personalisation of device selection and the optimal intensity and duration of DAPT? It is commonly recognised that these decisions must be individualised, taking into account the competing risks of thrombosis and bleeding. With respect to device selection, given their superior efficacy and safety, new-generation DES should be preferred to BMS. With respect to pharmacotherapy, in line with the "primum non nocere" principle, bleeding risk characterised with the LEADERS FREE inclusion criteria ${ }^{7}$ or available risk scores $^{8}$ should be the first factor to take into account when deciding upon the mandatory duration of DAPT. After this, parameters such as index clinical presentation, procedural complexity and the residual atherothrombotic risk quantified with available thrombotic risk scores ${ }^{8}$ should all be taken into account concomitantly in order to estimate the potential net clinical benefit of extended DAPT. A stepwise approach to guide the choice of the optimal DAPT duration taking into account the factors mentioned above is illustrated in Figure 1. Further research is needed to improve the profiling of HBR patients and optimise

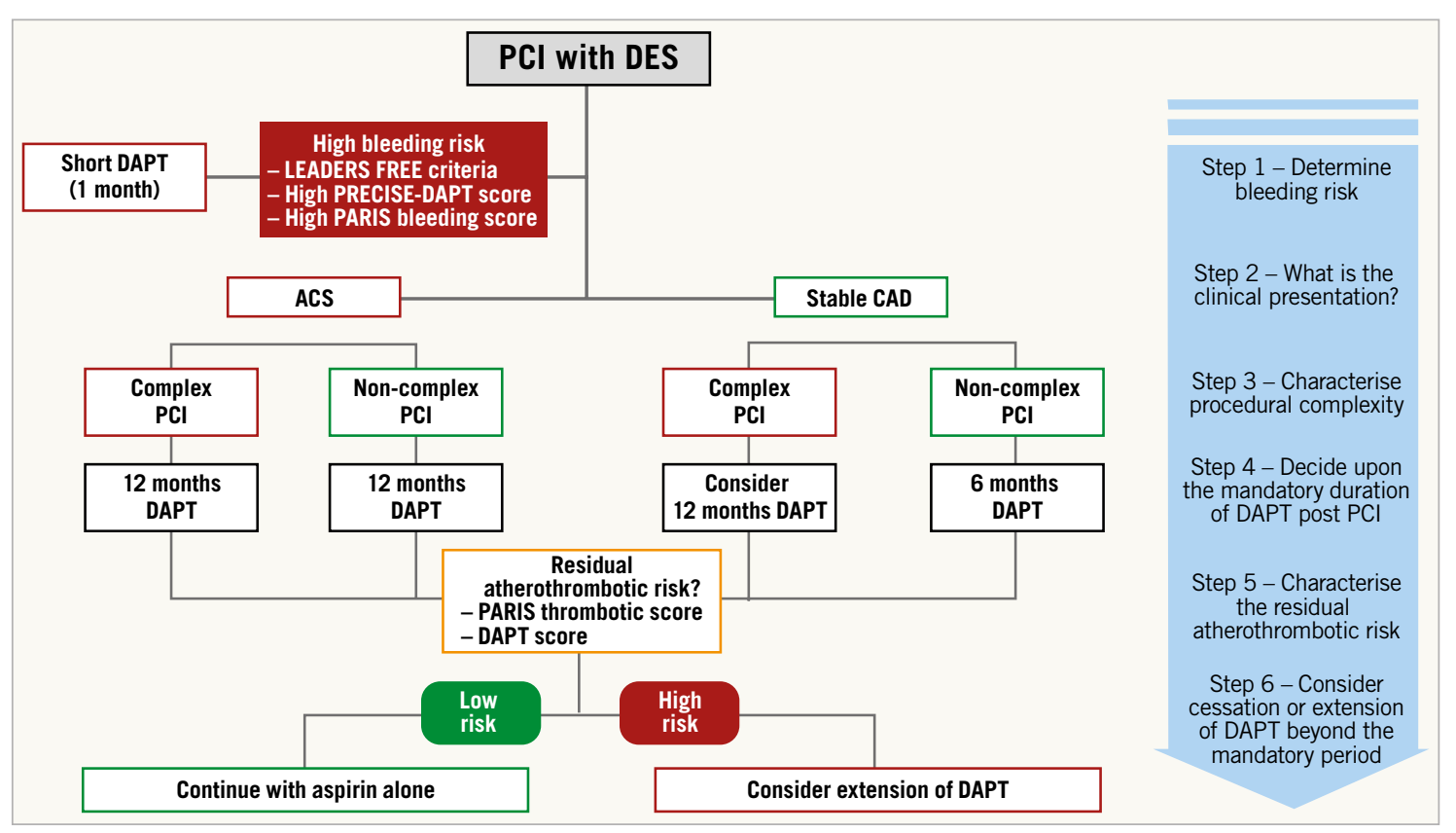

Figure 1. Decision-making algorithm for DAPT duration integrating bleeding risk, procedural complexity and the acuteness of clinical presentation. 
the complex device-pharmacotherapy interaction for this unique and challenging subset of patients previously excluded from randomised controlled trials.

\section{Conflict of interest statement}

R. Mehran or her spouse has received institutional research grant support from The Medicines Company, Bristol-Myers Squibb, Sanofi-Aventis, Eli Lilly and AstraZeneca, and consulting fees from AstraZeneca, Bayer, CSL Behring, Janssen Pharmaceuticals Inc., Merck \& Co., Osprey Medical Inc., and Watermark Research Partners, and serves on the advisory board of Abbott Laboratories, Boston Scientific Corporation, Covidien, Janssen Pharmaceuticals Inc., The Medicines Company, and Sanofi-Aventis. The other author has no conflicts of interest to declare.

\section{References}

1. Gibson CM. Going Polymer Free and Dual Antiplatelet Free Earlier: The Coevolution of Stent and Pharmacotherapy. J Am Coll Cardiol. 2017;69:172-5.

2. Giustino G, Baber U, Sartori S, Mehran R, Mastoris I, Kini AS, Sharma SK, Pocock SJ, Dangas GD. Duration of dual antiplatelet therapy after drug-eluting stent implantation: a systematic review and meta-analysis of randomized controlled trials. $J \mathrm{Am}$ Coll Cardiol. 2015;65:1298-310.

3. Généreux P, Rutledge DR, Palmerini T, Caixeta A, Kedhi E, Hermiller JB, Wang J, Krucoff MW, Jones-McMeans J, Sudhir K, Simonton CA, Serruys PW, Stone GW. Stent Thrombosis and Dual Antiplatelet Therapy Interruption With Everolimus-Eluting Stents:
Insights From the Xience V Coronary Stent System Trials. Circ Cardiovasc Interv. 2015 May;8(5).

4. Généreux P, Giustino G, Witzenbichler B, Weisz G, Stuckey TD, Rinaldi MJ, Neumann FJ, Metzger DC, Henry TD, Cox DA, Duffy PL, Mazzaferri E, Yadav M, Francese DP, Palmerini T, Kirtane AJ, Litherland C, Mehran R, Stone GW. Incidence, Predictors, and Impact of Post-Discharge Bleeding After Percutaneous Coronary Intervention. J Am Coll Cardiol. 2015;66: 1036-45

5. Giustino G, Chieffo A, Palmerini T, Valgimigli M, Feres F, Abizaid A, Costa RA, Hong MK, Kim BK, Jang Y, Kim HS, Park KW, Gilard M, Morice MC, Sawaya F, Sardella G, Genereux P, Redfors B, Leon MB, Bhatt DL, Stone GW, Colombo A. Efficacy and Safety of Dual Antiplatelet Therapy After Complex PCI. $J$ Am Coll Cardiol. 2016;68:1851-64.

6. Yeh RW, Kereiakes DJ, Steg PG, Cutlip DE, Croce KJ, Massaro JM, Mauri L; DAPT Study Investigators. Lesion Complexity and Outcomes of Extended Dual Antiplatelet Therapy After Percutaneous Coronary Intervention. J Am Coll Cardiol. 2017;70: 2213-23.

7. Lipiecki J, Brunel P, Morice MC, Roguelov C, Walsh S, Richardt G, Eerdmans P, Zambahari R, Berland J, Copt S, Stoll HP, Urban P. Biolimus A9 polymer-free coated stents in high bleeding risk patients undergoing complex PCI: evidence from the LEADERS FREE randomised clinical trial. EuroIntervention. 2018;14:e418-25.

8. Capodanno D, Angiolillo DJ. Tailoring duration of DAPT with risk scores. Lancet. 2017;389:987-9. 